College. The ballot paper shall not indicate the method of nomination or the names of those nominating. If the number of nominees does not exceed the number of vacancies, these nominees shall be declared elected at the first meeting, whether of the Council or of the Executive and Finance Committee, after the expiry of the period of four clear weeks in this paragraph referred to.

\section{The Royal Court offers members reduced-price tickets for Iron by Rona Munro between 22 January and 1 March 2003}

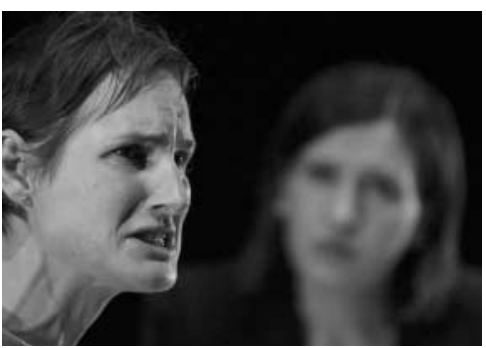

The Royal Court, Sloane Square, London SW1 is offering members of the College $\mathrm{f2}$ off the top 2 price bands for Iron (excluding Mondays), a play by Rona Munro, directed by Roxana Silbert.

Iron was previously performed at the Edinburgh Fringe Festival. 'Josie is visiting her mother Fay in prison for the first time. She's not seen her for 15 years, not since the day her mother was taken away when she was 10 years old. Fay is in prison for murder. A murder Josie cannot remember and Fay has always tried to forget.' "This is a psychological drama at its best tense, harrowing, yet also powered by an unsentimental fund of compassion." Daily Telegraph. "Roxana Silbert's production is exquisitely judged . . . beautifully acted." Guardian.

Please book reduced-price tickets ( $f 24$ or $f 17.50)$ through the priority booking line. Tel: 0207565 5005, quoting 'Royal College of Psychiatrists'. This play has been supported by the College through the Mind Odyssey initiative.

\section{Acute Psychiatric Care For Young People With Severe Mental Illness CR106}

\section{Summary}

This document has been produced by working group of the Faculty of Child and Adolescent Psychiatry and the Faculty of General and Community Psychiatry. It makes recommendations about how services should be provided and commis sioned, for the acute care of young people with serious mental illness.

There is widespread recognition that the care of young people presenting with acute, severe mental illness is often unsatisfactory. This can be due to a lack of any suitable bed, undue delay, or an inappropriate admission to an adult or paediatric bed. In fact, some 600 young people are inappropriately placed per year, in England and Wales, on adult or paediatric wards.

The report notes that the principles of specialist provision for adolescents with serious mental illness should include prompt admission, a suitably safe and appropriately staffed ward environment which conforms to the agreed standards), geographical proximity to the family home (enabling frequent visits and appropriate family interventions to be offered), and minimisation of health and safety risks from other patients and drugs and alcohol availability.

The key recommendations are that:

- Young people under 16 years should not be admitted to adult psychiatric wards

- Those aged 16 or 17 years of age can be considered for admission to adult psychiatric wards when

- no suitable specialist adolescent psychiatric bed is available

- they are suffering from severe mental illness

- acceptable standards of care are met

- Health commissioners need to develop appropriate services

- Inappropriate admissions should be considered as a sign of inadequate resources and treated as an untoward or critical incident.

The report concludes that significant investment and development is needed to provide acute inpatient and community services for adolescents with severe mental illness in line with Government priorities

\title{
obituary
}

\section{Dr Alexander Getty Fullterton}

Formerly Medical Director of Barnsley Hall Hospital, Bromsgrove.

Alec Fullerton was born and raised in Ballymena, County Antrim, one of five children all destined for the medical profession. He attended Ballymena Academy, where his father was headmaster. With both parents teachers, he was expected to excel and he duly obliged. In emerging from school, at the age of 17, he enrolled as a medical student at Queen's University, Belfast. Five months later, being now 18, he volunteered for the Royal Navy. There was no conscription in Northern Ireland, but Alec felt his duty very strongly. After initial Naval training, he was sent on a rigorous course at King Alfred Officer Training Centre in Hove and he was commissioned as a sub-lieutenant, choosing to serve in minesweepers for the rest of the war.

When he was released in December 1946, he returned to Queen's where he took an active part in university life, being a rowing cox and an enthusiastic rugby player. After qualifying, he embarked on the usual junior posts but in 1953, on the advice of his elder brother, who was in general practice in Dorset, he moved to England.

Alec had decided to specialise in psychiatry and was offered a post at Herrison Hospital, Dorchester, where he received excellent progressive training. He flourished here and quickly gained his DPM. While at Herrison he was extremely

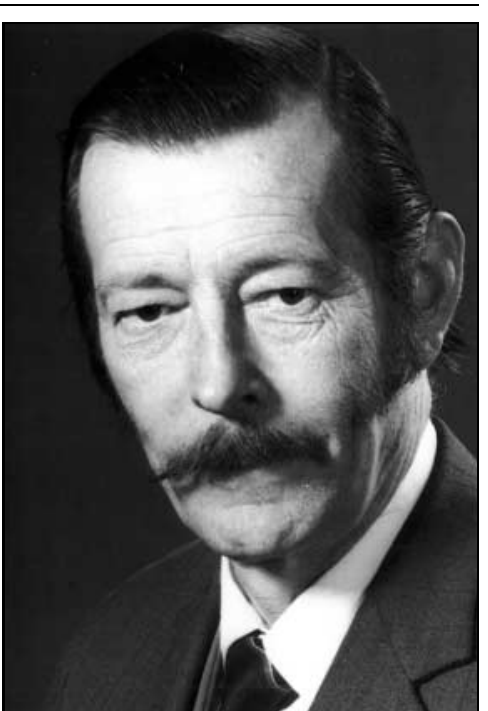

